\title{
PENGETAHUAN LOKAL IBU HAMIL TENTANG TANDA BAHAYA KEHAMILAN DAN PERSALINAN DI PUSKESMAS ALALAK TENGAH KOTA BANJARMASIN
}

\author{
LOCAL KNOWLEDGE OF PREGNANT WOMEN ABOUT THE DANGER OF PREGNANCY \\ AND CHILDBIRTH ALALAK DOWNTOWN BANJARMASIN IN PUBLIC HEALTH
}

\author{
Husnul Khatimatun Inayah \\ Fakultas Kesehatan Masyarakat, Universitas Islam Kalimantan (UNISKA) MAB Banjarmasin \\ Jl. Adhyaksa, Jl. Kayu Tangi 1 Jalur 2 No.2. Kota Banjarmasin, Kalimantan Selatan \\ Email : husnulhlf@gmail.com
}

\begin{abstract}
According to the 2002-2003 Indonesian Demographic Health Survey (IDHS) MMR in Indonesia is still quite high, namely: 307 / 100,000 births. The condition of "4 late" where, late in recognizing danger signals, is one of the causes. Delay in recognizing danger signs because of the lack of knowledge of pregnant women about the danger signs of pregnancy and childbirth that have an impact on increasing maternal mortality. Bappenas (2015). Local knowledge derived from traditional cultural practices influences maternal mortality. This study aims to determine the local knowledge of pregnant women about danger signs of pregnancy and childbirth in the city of Banjarmasin. Type of qualitative research with ethnographic design. Results Research into pregnant women is familiar with the knowledge of danger signs of pregnancy and childbirth through taboos performed during pregnancy and childbirth. Some local knowledge about the danger signs of pregnancy and childbirth are conflicting and some are not contradictory and those that support health. It is recommended for health workers, especially midwives to further increase the knowledge of pregnant women about danger signs during pregnancy and childbirth through counseling, counseling to align local knowledge that is contrary to health, and motivate pregnant / childbirth women to continue implementing culture / habits that support health.
\end{abstract}

Keyword: Local Knowledge; Danger Sign; Pregnancy and Cchildbirth

\begin{abstract}
Abstrak
Menurut Survei Demografi Kesehatan Indonesia (SDKI) 2002-2003 AKI di Indonesia masih cukup tinggi yaitu: 307/100.000 kelahiran. Kondisi“4 terlambat” dimana, terlambat mengenali tanda bahaya, merupakan salah satu penyebabnya. Terlambat mengenali tanda bahaya dkarena kurangnya pengetahuan ibu hamil tentang tanda bahaya kehamilan dan persalinan yang berdampak meningkatnya kematian ibu. Bappenas (2015). Pengetahuan lokal yang berasal praktik-praktik budaya tradisional berpengaruh terhadap kematian ibu. Penelitian ini bertujuan mengetahui pengetahuan lokal ibu hamil tentang tanda bahaya kehamilan dan persalinan di Puskesmas Alalak Tengah Kota Banjarmasin. Jenis penelitian kualitatif dengan rancangan etnografi. Hasil Penelitian ibu hamil mengenal pengetahuan tentang tanda bahaya kehamilan dan persalinan melalui pantangan yang dilakukan saat hamil dan melahirkan. Sebagian pengetahuan lokal tentang tanda bahaya kehamilan dan persalinan ada yang bertentangan dan ada yang tidak bertentangan serta adapula yang mendukung kesehatan. Disarankan kepada tenaga kesehatan terutama bidan untuk lebih meningkatkan pengetahuan ibu hamil tentang tanda bahaya saat hamil dan bersalin melalui penyuluhan, konseling untuk meluruskan pengetahuan lokal yang bertentangan dengan kesehatan, dan memberikan motipasi pada ibu hamil/bersalin untuk terus melaksanakan budaya/kebiasaan yang mendukung kesehatan.
\end{abstract}

Kata Kunci: Pengetahuan lokal; Tanda Bahaya; Kehamilan/Persalinan 


\section{PENDAHULUAN}

Millennium Development Goals (MDG`s) atau tujuan pembangunan millenium merupakan komitmen Indonesia bersama 188 negara lain anggota PBB untuk dijadikan acuan pelaksanaan pembangunan bagi setiap negara. MDG's mempunyai delapan tujuan pembangunan. Tujuan $M D G^{\prime}$ 's untuk pembangunan kesehatan ada 3, salah satunya adalah meningkatkan kesehatan ibu yang mempunyai target menurunkan Angka Kematian Ibu (AKI) sebesar (75\%) antara tahun 1990 sampai tahun 2015, Fakta dilapangan AKI masih belum seperti yang diharapkan dan naik turun dari tahun 2015 sampai dengan 2019 (1). Penyebab tidak langsung kematian ibu seperti: rendahnya status gizi ibu hamil (anemia 51\%) dan "4 terlalu" (60,6\%) yaitu: terlalu muda, terlalu tua, terlalu sering dan terlalu banyak serta kondisi " 3 dan 4 terlambat" yaitu: terlambat mengenali tanda bahaya, terlambat mengambil keputusan, terlambat mencapai fasilitas rujukan dan terlambat memperoleh kualitas pelayanan yang memadai $(2,3,4)$.

Terlambatnya mengenali tanda bahaya disebabkan kurangnya pengetahuan ibu mengenai tanda bahaya kehamilan yang berdampak pada meningkatnya kematian ibu (4). Penyebab kematian ibu sangat terkait dengan tradisi budaya. Kondisi sosial budayalah yang sebenarnya memegang peranan utama pada tingginya AKI (5).

Penelitian di Purworejo Jawa Tengah menemukan adanya persepsi yang tidak sama tentang penyulit kehamilan dan persalinan seperti bayi besar, letak sungsang, usia ibu lebih 35 tahun pada persalinan pertama, paritas lebih dari 5, jarak kehamilan kurang dari 2 tahun, umur bersalin kurang dari 20 tahun tidak dianggap sebagai penyulit (6).

Upaya pemerintah Indonesia untuk meningkatkan pengetahuan dan memberdayakan ibu hamil dan keluarga melalui kerjasama Depkes dengan badan kesehatan dunia World Health Organization (WHO) berinisiatif melakukan suatu strategi untuk menanggulangi masalah tersebut dengan Making Pregnancy Safer (MPS). MPS berfokus pada ketersediaan pelayanan yang memadai dan berkelanjutan. Salah satu dari empat strategi MPS adalah mendorong pemberdayaan wanita dan keluarga melalui peningkatan pengetahuan dan perilaku sehat7. Upaya lain pemerintah dalam meningkatkan pengetahuan dan kemandirian masyarakat untuk berperilaku sehat adalah melaksanakan program kesehatan ibu dan anak melalui SK MENKES No 284/MENKES/SK/III/2004 tentang Buku Kesehatan Ibu dan Anak (Buku KIA). Buku KIA merupakan alat informasi kesehatan untuk ibu hamil dan anak yang dikandungnya termasuk tanda bahaya saat kehamilan persalinan dan nifas 8 . Dalam memberikan informasi kesehatan kepada masyarakat/ibu hamil, sangat penting memperhatikan aspek budaya agar informasi yang diberikan dapat diterima dengan baik. Budaya/tradisi sangat berpengaruh terhadap perilaku kesehatan individu/masyarakat yang terdapat dalam predisposisi faktor (10).

Jumlah kematian ibu di Kalimantan Selatan tahun 2017 sebanyak 49/1000 kelahiran dan tahun 2018 sebanyak 47/1000 kelahiran dengan penyebab utama perdarahan preeklamsia dan eklamsia (Dinkes Propinsi Kalimantan Selatan, 2018). Jumlah kematian ibu di Banjarmasin tahun 2017 sebanyak 5 /1000 kelahiran dan tahun 2018 sebanyak 8/1000 kelahiran, (Profil Kesehatan Kota Banjarmasin, 2018) (11).

Upaya Pemerintah menurunkan kematian ibu dengan mengenal secara dini tanda bahaya kehamilan dan persalinan. Pentingnya pengetahuan untuk mengenal tanda bahaya pada kehamilan, persalinan dan nifas agar ibu hamil dan keluarga dapat mengenali sedini mungkin dan waspada terhadap ancaman yang mungkin timbul pada saat kehamilan, persalinan dan nifas (4).

Berdasarkan uraian di atas, riset ini dilakukan untuk menggali pengetahuan lokal ibu hamil tentang tanda bahaya kehamilan dan persalinan.

\section{BAHAN DAN METODE}

Penelitian ini adalah penelitian dengan metode kualitatif. Rancangan penelitian adalah studi etnografis, untuk dapat menggali secara mendalam pengetahuan lokal ibu-ibu hamil tentang tanda bahaya kehamilan di Banjarmasin. Populasi penelitian adalah ibu-ibu hamil di wilayah kerja Puskesmas Alalak tengah kota Banjarmasin yang melakukan kunjungan ke Puskesmas Alalak Tengah atau ke tenaga kesehatan di wilayah selama hamil selama bulan agustus sampai oktober. Untuk menambah data informan kunci diambil dari tokoh masyarakat di sekitar ibu hamil yang mempraktikan budaya lokal itu. 
Pengumpulan data dalam penelitian ini dilakukan dengan metode observasi, FGD atau diskusi kelompok terarah (DKT), dan wawancara yang telah disusun sesuai dengan tujuan penelitian dan disesuaikan dengan kriteria inklusi dan ekslusi yang telah ditetapkan. Analisa data dilakukan secara non statistik sesuai dengan rancangan penelitian. Analisis data dilakukan dengan menggunakan analisis tema, dimana mulai menganalisis dari domain ke analisis tema.

\section{HASIL DAN PEMBAHASAN}

Pengetahuan Lokal Ibu hamil tentang tanda bahaya kehamilan dan persalinan.

Pantangan Pada Saat kehamilan

Ibu hamil pada suku Banjar mengenal tanda bahaya dalam kehamilan dan persalinan melalui pantangan-pantangan yang dilaksanakan baik pada saat kehamilan dan persalinan/setelah bersalin. Pantangan yang dilakukan pada saat hamil dan melahirkan adalah pantangan makanan dan kegiatan. Pantangan makanan antara lain berupa: pantang makan buah, pantang makan sayur yang menjalar, pantang makan ikan berduri dan pantang minum es.

Pantangan kegiatan pada saat hamil berupa: pantang masuk rumah melewati pintu samping atau belakang, pantang tidur bolak-balik, pantang mandi malam dan keluar malam, pantang terinjak darah ikan, Pantang melilitkan kerudung di leher, melilitkan handuk di kepala dan mengikat sarung di bahu dan pantang bepergian melalui sungai besar atau lautan.

Pantangan ini dimaksudkan agar selama hamil dan bersalin ibu dan bayi terhindar dari keadaan yang dapat membahayakan ibu selama kehamilan dan persalinan. Pendapat ini diperoleh dari informan hasil wawancara dan peserta FGD sebagai berikut:

"Amun nang ulun tahu kada bahaya ka, tapi pantangan yang digawi atau nang dimakan urang batianan supaya kada membahayaakan diri lawan anaknya"(I.2)/ (D.5)

Artinya:

"Kalau yang saya tahu bukan bahaya, tapi ibu hamil harus mengerjakan pantangan-pantangan agar terhindar dari bahaya pada saat hamil dan melahirkan"

\section{Pantangan sesudah persalinan}

Pantangan setelah melahirkan ditujukan agar ibu post partum tetap sehat dan terhindar dari kalalah. Kalalah adalah istilah yang digunakan pada ibu post partum yang mengalami gajala-gejala sakit panas dingin, seluruh tubuh terasa pegal-pegal, kepala pusing dan mual.

Kalalah ada beberapa macam sesuai dengan penyebabnya masing-masing misalnya kelalah makanan disebabkan ibu post partum salah makan, kelalah ari disebabkan ibu post partum terkena panas matahari atau kena air hujan, kelalah api disebabkan ibu post partum terlalu kena cahaya panas api di dapur dan kelalah laki disebabkan melakukan hubungan suami istri pada masa berpantang sampai 40 hari setelah persalinan. Pengetahuan ini diperoleh dari peserta FGD sebagai berikut:

"kelalah itu yang awak pina sakitan, mariap dingin, kepala sakit amun pina bepanas itu kelalah ari, amun dipadang api haja, kalalah api bisa karena kepanasan, salah makan kalalah makanan, kalalah laki dianu laki balum ganap"(D:1)

Artinya:

"Tanda-tanda kalalah adalah seluruh badan terasa sakit, panas dingin, kepala sakit, bila terlalu berjemur dipanas matahari disebut kalalah ari, bila terlalu masak didapur disebut kalalah api, kelalah makanan karena salah makan dan kalalah laki berhubungan suami istri selama masa berpantang"

Berpantang makanan setelah melahirkan selain ditujukan terhindar dari kalalah juga ditujukan agar luka jalan lahir cepat sembuh, dan involusi rahim berjalan lancar. Pendapat ini dikemukakan sebagian besar ibu hamil, hal ini dapat dikutip dari informan hasil FGD sebagai berikut:

"sampai 2 bulan tu pang hanyar wani bememakan, pokoknya imbah beranak tu kada wani memakan nang liur nyaman, supaya luka dalam lakas waras" (D:5)

Artinya:

"Sampai 2 bulan baru berani makan, pokoknya setelah bersalin tidak berani makan yang enak, supaya luka dalam lekas sembuh"

Sebagian besar ibu hamil masih memgang teguh pantangan terutama ibu hamil yang berpendididkan SD dan SMP. Sebagian lagi sudah tidak mematuhi pantangan yang diharuskan terutama ibu hamil yang berpendidikan SMA.

Seperti pantangan makan ikan pada ibu bersalin dilanggar oleh sebagian kecil ibu dengan alasan pantangan tersebut tidak sesuai dengan jalan pikiran ibu. 
"Ikan sebenarnya berpantang juga ka yang boleh hanya tahu tempe dan telor, cuman kemarin alasan berpantangnya kalo aku pikir ngga masuk jalan pikiran ku ka jadi aku makan sedikit-sedikit ikan walau dilarang" (I:2)

Artinya:

"Ikan seharusnya berpantang yang boleh hanya tahu, tempe dan telur. Cuman kemarin alasan berpantangnya, aku pikir ngga masuk jalan pikiran ku ka, jadi aku makan sedikit-sedikit ikan walau dilarang.

Kondisi yang dianggap tidak berbahaya dalam kehamilan dan persalinan dalam budaya Banjar.

Dalam masyarakat Banjar terdapat kondisi yang dianggap tidak membahayakan ibu hamil dan bersalin seperti: Kambar banyu (ketuban pecah dini), Bengkak tangan dan kaki pada saat akhir kahamilan, Payudara bengkak dan merah setelah bersalin, Keluar cairan berbau di jalan lahir. Informasi ini diperoleh dari informan hasil FGD sebagai berikut: "yang temasuk kada tapi bebahaya kambar banyu kadapapa, meruyan babau kurang jamu, susu bangkak lawan bangkak tangan dan batis itu tanda parak baranak" (D:3)

Artinya:

"Keadaan yang dianggap tidak bahaya seperti kembar banyu engga apa-apa, cairan berbau pada jalan lahir karena kurang jamu, susu bengkak dan bengkak kaki dan tangan biasanya tanda akan melahirkan"

Kondisi ini tidak membahayakan kesehatan ibu hamil kerana dianggap keadaan yang biasa terjadi pada saat hamil dan melahirkan.

\section{Pengetahuan medis tentang tanda Bahaya kehamilan dan persalinan.}

Selain mengenal tanda bahaya pada saat kehamilan dan persalinan dalam budaya Banjar, ibu hamil juga mengenal tanda bahaya dalam kehamilan dan persalinan menurut konsep medis. Tanda bahaya yang mereka ketahui antara lain: Bayi tidak bergerak dalam kandungan, Ibu tidak kuat mengedan mengalami kejang, Demam lebih 2 hari pada saat nifas dan Mengalami gangguan jiwa setelah bersalin. Pengetahuan ini diperoleh dari informan wawancara dan peserta FGD sebagai berikut: "kakanak kada bagarak dalam kandungan, kada kuat bahajan lawan kejang itu biasanya darah tinggi, panas lebih 2 hari imbah baranak itu kalalah lawan mamanya gila tadi" ( D:2)

Artinya:

"Bayi tidak bergerak dalam kandungan, Ibu tidak kuat mengedan mengalami kejang itu biasanya darah tinggi, Demam lebih 2 hari pada saat nifas itu kalalah dan ibu yang gila setelah bersalin"

\section{Kebiasaan-kebiasaan yang dilakukan pada saat hamil dan melahirkan.}

Adat kebiasaan pada saat kehamilan

Dalam budaya Banjar banyak ritual upacara yang dilakukan pada ibu hamil dan diantaranya: Upacara Tian mandaring/Bapagar mayang/bamandi-mandi, mandi sembilan, mandi baya, dan minta banyu pulau atau sungai. Keseluruhan upacara ini bertujuan agar ibu hamil dan bayi selamat dalam masa kehamilan dan persalinan. Informasi ini didapat dari informan hasil FGD dan wawancara sebagai berikut:

"mandi-mandi supaya melahirakan kada bebahaya selamat mama lawan anaknya" (D:3)

Artinya:

"Dengan upacara mandi-mandi diharapkan melahirkan normal selamat ibu dan bayinya"

Kebiasaan saat persalinan

Apabila ibu hamil memasuki masa persalinan kebiasaan yang dilakukan adalah menyiapkan ruangan yang akan menjadi tempat bersalin berupa ruangan/kamar dipasang ijuk/haduk, memasang daun nenas dibawah kamar, membeli tanah/menukar tanah bagi rumah yang belum pernah dilahiri bayi dan meminta air/ Banyu pelungsur. Persiapan ini dilakukan untuk melindungi ibu dari gangguan mahluk halus/jin yang dapat mengganggu persalinan atau untuk keselamatan ibu yang akanbersalin. Di bawah ini pernyataan tentang air/banyu pelungsur sampaikan oleh peserta FGD sebagai berikut:

"handak beranak minta banyu pelungsur lawan bidan kampung supaya kada halinan" (D:5)

Artinya:

"Bila mau melahirkan minta air pelungsur dengan dukun beranak supaya melahirkan tidak sulit"

Pernyataan tentang pentingnya ijuk dipasang di kamar tempat bersalin sebagai berikut:

"bahaduk ulun ia jua dirumah tuh. diandak dietiap lawang. Supaya jangan diharu-harunya" (D:1) 
Artinya:

"Rumah saya dipasang haduk, ditaruh disetiap jendela dan pintu supaya tidak di ganggu"

Dalam proses peralinan ibu biasanya didampingi oleh keluarga atau orang terdekat ibu seperti orang tua atau saudara. Pada masa kini pendampingan ini berkembang, selain keluarga suami pun dapat menjadi pendamping dalam persalinan apabila diinginkan, seperti yang terjadi pada salah seorang informan wawancara dan observasi sebagai berikut:

"laki ulun manunggui sambil maangkatakan kapala ulun dirusuh bidan suruh bidan bila bahajan, membujurakan awak bila taturun" (I:3)

Artinya:

Suami saya menunggu saya saat melahirkan sambil mengangkatkan kepala saya saat mengedan bila disuruh bidan, dan membetulkan badan saya yang melorot kebawah.

Apabila persalinan dianggap berjalan lama dalam budaya Banjar dilakukan ritual bedudus dan dilangkah laki agar persalinan dapat berjalan kembali normal. Istilah bedudus adalah membelah kelapa di atas perut ibu yang sedang bersalin, setelah terbelah air kelapa diguyurkan dari atas kepala sampai kaki. Di langkah laki adalah istilah untuk suami yang melangkah diatas tubuh ibu yang sedang bersalin. Salah seorang peserta FGD menyatakan bahwa masih memegang teguh adat bedudus apabila persalinan menjadi lama, hal ini dapat dikutip dari Informan hasil FGD:

"pas beranak halinan tunah dipacah nyiur dicatas parut mamanya kalo dianuakan biasanyalah banyunya dari atas sampai kebawahlah, eeh patuh badudus jurang" (D:3)

Artinya:

Bila susah bersalin dibelah kelapa diatas perut ibu bersalin dan airnya diguyurkan dari kepal sampai kaki, aku sering badudus.

Sebagian besar peserta FGD menyatakan bila terjadi persalin lama mereka tidak lagi melakukan ritual dudus tapi melakukan kebiasaan di langkah laki, hal ini dilakukan karena berkembang kepercayaan bahwa salah satu penyebab persalinan lama disebabkan karena kualat dengan suami. Informasi ini didapat dari informan peserta FGD:

Informasi serupa juga disampaikan oleh peserta FGD lainnya sebagai berikut: "melahirakan sulit kalo pina katulahan apakah, jadi dilangkahi lawan laki haja mun badudus kami kada lagi" (D:1)

Artinya:

Melahirkan sulit itu bisa saja disebabkan kualat dengan suami, jadi dilangkah saja dengan suami supaya mudah melahirkan, tapi kalau bedudus kami tidak mengerjakan lagi.

\section{Kebiasaan yang dilakukan setelah persalinan}

Setelah persalinan dilakukan ritual seperti mengazdankan bayi. Agar bayi terhindar dari gangguan mahluk halus diletakan benda-benda seperti: Surah Yasiin, jeruk nipis dan cermin dan membakar bahan-bahan seperti daun jeriangau, bawang merah tunggal, daun sirsak (serapangan) pada senja hari. Berikut ini pendapat tentang bendabenda yang diletakan diatas kepala bayi sebagai berikut:

"Pokoknya sebarataan tu yasiin, limau nifis, ceramin gasan menusir urang halus tadi pang" (D:8)

Artinya:

"Pokoknya semua itu yasin, jeruk nifis, cermin untuk mengusir mahluk jin"

Perlakuan terhadap ari-ari bayi yaitu memasukan ari-ari dalam kapid yang diisi dengan garam, kertas dan pensil supaya anak pintar, mengubur ari-ari di depan rumah di bawah pohon pisang atau mangga dengan maksud agar bayi kelak menjadi orang sabar dan disenangi orang. Pada saat mengubur di atas kuburan diberi selumbung air yang bertujuan agar ari-ari dapat bernafas. Dalam mengubur hal yang perlu diperhatikan adalah kuburan jangan kena hujan. Informasi ini dapat dikutif dari peserta FGD:

"selumbungan banyu, paring ada kalo paring halus tu nah , supaya inya kawa bahinak jar" (D:3)

Artinya:

Selumbung air, terbuat dari pohon bambu yang kecil, supaya ari-ari bisa bernafas.

Setelah tali pusat bayi puput dilakukan ritual Tapung tawar dan palas bidan. Dalam budaya Banjar tapung tawar dikenal sebagai upacara penyerahan anak dari bidan kepada ibu bersalin. Upacara ini dilakukan setelah tali pusat bayi puput karena dengan puputnya tali pusat ibu dianggap akan bisa merawat sendiri anaknya. Pengetahuan ini di dapat dari peserta FGD sebagai berikut: 
"tapung tawar tu penyerahan bayi, amun palas bidan tu penyerahan piduduk gasan penukar uyuh bidan, inya kesahnya bayi kita yang di lahirkan bidan tu masih anak bidan, jadi diserahkan pulang wadah kita jadi anak kita" (D:3).

Artinya:

tapung tawar tu penyerahan bayi, kalo palas bidan tu penyerahan piduduk untu penukar cape bidan, ceritanya bayi yang kitai lahirkan itu masih anak bidan, jadi diserahkan kembali dengan kita supaya jadi anak kita.

Palas bidan adalah penyerahan piduduk untuk bidan. Piduduk ini diserahkan untuk penukar jasa bidan atas perawatan yang diberikan pada ibu bersalin dan bayi. Piduduk berupa perlengkapan pangan untuk bidan yang berupa beras, rempah dapur, bawang merah, bawang putih, jarum, benang, kelapa, gula merah dan putih dan lain-lain, hal ini dapat dikutip dari informan peserta FGD sebagai berikut:

"Beras, nyiur, gula habang rampah dapur (bawang putih ,habang,sahang,dll yang diserahkan gasan palas bidan untuk menabus jasa bidan lawan anak dan kita jua ai" (D:3)

Artinya:

Beras, kelapa, gula merah, rempah dapur (bawang putih / merah, lada, dll yang diserahkan untuk palas bidan untuk menebus jasa bidan pada anak dan kita sendiri.

Hasil Penelitian Pengetahuan lokal ibu hamil tentang tanda bahaya kehamilan terdapat kebiasaan ibu hamil suku Banjar yang bertentangan dengan kesehatan atau aspek medis seperti: pantangan makan ikan segar/laut, sayur dan buah terutama pada saat post partum. Pada saat post partum sangat diperlukan nutrizi yang bermutu tinggi denga cukup kalori, protein, cairan serta banyak buah-buahan berguna untuk pemulihan tenaga, penyembuhan luka jalan lahir dan nurtisi bagi bayi (12). Berpantang dalam waktu lama berakibat buruk terhadap kesehatan ibu dan bayi. Berdampak meningkatnya kesakitan pada ibu dan bayi. Pantangan untuk membawa bayi keluar rumah sebelum tapung tawar 0-9 hari bertentangan dengan kesehatan karena pada saat ini adalah waktu yang tepat bayi mendapat imunisasi BCG agar terhindar dari penyakit TBC.

Pantangan ini cenderung lebih ditaati oleh ibu-ibu yang berpendidikan rendah. Mereka beranggapan selama mereka mentaati pantangan tersebut tidak akan pernah terjadi hal-hal yang membahayakan bagi diri mereka. Hal ini pula yang dilakukan oleh nenek moyang mereka. Mereka takut melakukan hal baru yang bertentangan dengan budaya yang telah diturunkan pada mereka. Keadaan ini berbeda dengan ibu hamil yang berpendidikan tinggi. Mereka lebih berani melakukan hal baru yang mereka anggap sesuai dengan kondisi saat ini. Pendidikan yang diperoleh sangat berpengaruh terhadap peningkatan pengetahuan kesehatan (10).

Sumber pengetahuan utama yang berguna untuk menurunkan angka kematian ibu berasal dari pendidikan formal di sekolah dan hasil interaksi masyarakat dengan kesehatan modern (5). Pendidikan yang rendah sangat berpengaruh terhadap pengetahuan ibu tentang tanda bahaya kehamilan dan persalinan khususnya berkaitan cara ibu menilai suatu kondisi/keadaan yang berbahaya bagi diri ibu sendiri.

Selain pendidikan lingkungan tempat ibu hamil tinggal juga berpengaruh terhadap ketaatan ibu hamil terhadap kebiasaan-kebiasaan termasuk pantangan yang harus dilaksanakan ibu selama hamil dan melahirkan. Ibu hamil berpendidikan SMA, tapi masih tinggal dengan orang tua akan tetap melaksanakan pantangan selama hamil dan melahirkan dibandingkan ibu yang berpendidikan SMA tapi sudah tinggal terpisah dengan orang tua. Pengalaman dalam melahirkan atau paritas berpengaruh terhadap ketaatan ibu terhadap pantangan seperti ibu yang baru pertama kali hamil akan lebih taat terhadap pantangan walaupun mempunyai pendidikan SMA, dibandingkan ibu yang sudah bepengalaman dalam kehamilan dan melahirkan.

Pengetahuan lokal dalam budaya Banjar yang bertentangan dengan kesehatan seperti kondisi yang dianggap tidak berbahaya untuk ibu hamil/bersalin misalnya: kambar banyu (ketuban pecah dini), bengkak kaki dan tangan pada saat hamil payudara bengkak setelah melahirkan, dan keluar cairan berbau dari jalan lahir. Adanya anggapan yang salah tentang batasan usia perkawinan.

Anggapan ini perlu diluruskan karena bertentangan dengan konsep medis. Dalam konsep medis kondisi-kondisi di atas dianggap berbahaya apabila terjadi pada ibu saat hamil dan melahirkan 
karena berakibat meningkatkan kematian ibu dan bayi. Hal ini sesuai dengan teori bahwa pengetahuan lokal sangat kuat pengaruhnya terhadap angka kematian ibu karena berasal dari praktik-praktik budaya tradisional dan keyakinan spiritual termasuk interpretasi terhadap ajaran agama (5). Salah satu penyebab kematian ibu dan bayi berhubungan dengan parktik-praktik kepercayaan budaya setempat termasuk bagaimana solusi yang diterapkan bagi wanita dan bayi baru lahir dirumah (4).

Hasil penelitian Pengetahuan lokal ibu hamil tentang tanda bahaya kehamilan dan persalinan ada yang tidak bertentangan dengan kesehatan.

Dalam budaya Banjar terdapat kebiasaan saat hamil dan bersalin yang tidak bertentangan dengan kesehatan seperti: pantangan minum es, kebiasaan ibu hamil pantang masuk rumah lewat samping, keluar malam dan mandi malam, pantang terinjak darah ikan, pantang melilitkan kerudung/handuk \& sarung di bahu, pantang menyeberangi sungai/lautan.

Pengetahuan akan pantangan pada saat hamil dan bersalin didapatkan ibu-ibu dari pengalaman yang mereka alami sendiri. Seperti kondisi diatas dimana ibu-ibu hamil melaksanakannya dan mereka merasa nyaman apabila melaksanakan hal tersebut. Mereka menganggap bila melaksanakan hal tersebut akan terhindar dari bahaya yang mungkin terjadi pada saat hamil dan melahirkan. Pengetahuan lokal adalah segala sesuatu yang diperoleh seseorang dari pengalaman kehidupannya sehari-hari sehingga membentuk kesadaran atau pengetahuan (13).

Selain kebiasaan pantangan dalam budaya Banjar adapula kebiasaan yang tidak bertentangan dengan kesehatan seperti melaksanakan upacara mandi-mandi pada kehamilan pertama, mandi baya pada kehamilan ganjil, dan sebagainya. Kebiasaan yang dilakukan pada bayi baru lahir seperti: mengadzankan, membakar serapangan dan palas bidan. Kebiasan ritual ini syarat makna antara lain adanya dukungan/perlindungan yang besar dari masyarakat dan keluarga terhadap ibu hamil dan melahirkan, kehamilan merupakan suatu hal yang harus dijaga dengan baik sehingga memperoleh keturunan yang diharapkan, motipasi masyarakat Banjar untuk mempunyai harapan hidup yang tinggi, berharganya anak dalam keluarga, pentingnya pendidikan bagi anak sebagai generasi penerus.

Budaya digambarkan sebagai suatu keseluruhan kompleks mengacu pada pola yang diajarkan dari karakteristik-karakteristik pemikiran dan perilaku dari suatu kelompok sosial. Termasuk di dalamnya agama, kekerabatan, pengetahuan, kepercayaan, seni, praktek-praktek akhlak dan kelahiran bayi (14). Adat istiadat/budaya adalah pengetahuan yang diperoleh dan digunakan orang untuk menginterpretasikan pengalaman dan melahirkan tingkah laku sosial ${ }^{15}$. Kebiasaan - kebiasaan ini tidak bertentangan dengan kesehatan karena apabila hal ini dikerjakan tidak membawa pengaruh buruk / tidak membahayakan kesehatan ibu dan bayi.

Hasil penelitian Pengetahuan lokal ibu hamil tentang tanda bahaya kehamilan dan persalinan terdapat kebiaasaan yang mendukung dengan kesehatan. Kebiasaan-kebiasaan ibu hamil suku Banjar yang mendukung kesehatan seperti: pendampingan saat persalinan dapat mempercepat persalinan yang sedang berlangsung. Minta banyu pelungsur terlihat besarnya dukungan secara psikologis yang diberikan oleh suami dan keluarga kepada wanita yang sedang bersalin. Secara psikologis wanita hamil dan melahirkan sangat peka/sensitive sehingga sangat memerlukan dukungan ini dan pantangan melakukan hubungan seks pada masa 40 hari setelah post partum memberikan efek positif bagi penyembuhan luka jalan lahir.

Dari kebiasaan budaya terbentuklah suatu pengetahuan lokal tentang reproduksi masyarakat Kal-Sel yang merupakan sebuah kearifan budaya setempat yang perlu dipelihara antara lain: 1) persalinan selalu melibatkan orang terdekat ibu yang akan memperkuat spirit/dukungan dalam persalinan. 2) adanya dukungan dari suami dan keluarga ketika akan melahirkan berupa berupa air pelungsur dan persiapan khusus dalam melahirkan ${ }^{5}$. Apabila kebiasaan ini dilakukan akan dapat memberikan efek positif / keuntungan bagi ibu yang sedang bersalin/post partum.

Selain kebiasaan, pengalamam dalam melahirkan (paritas) dan interaksi ibu dengan pelayanan kesehatan merupakan salah satu cara ibu mengenal pengetahuan tentang tanda bahaya dalam kehamilan dan persalin yang mendukung kesehatan. Sebagian besar ibu hamil suku Banjar khususnya kelompok 
ibu hamil yang berpendidikan SMP dan SMA mengenal tanda bahaya kehamilan dan persalinan sesuai konsep medis. Contoh pengetahuan tanda bahaya pada saat hamil dan bersalin yang mereka kenal melalui pengalamannya adalah bayi yang gerakannya kurang atau tidak bergerak dalam kandungan, ibu darah tinggi, mengalami kejang dan tidak kuat mengedan saat bersalin. Pengetahuan ini diperoleh baik dari pengalaman mereka sendiri atau berdasar pengalaman orang lain. Hal ini sesuai dengan pernyataan bahwa pengetahuan bersumber dari pengalaman, guru, orang tua, teman, buku, dan medis masa (16).

Kebiasaan yang positif pada saat kehamilan dan persalinan dalam budaya Banjar dan sebagian pengetahuan tentang tanda bahaya kehamilan dan persalinan konsep medis yang telah diketahui ibu perlu didukung/dilestarikan. Kondisi ini sangat berguna meningkatkan pengetahuan dan kesadaran ibu hamil tentang bahaya yang mungkin terjadi pada saat hamil dan melahirkan. Berdampak mengurangi bahaya yang mungkin timbul pada saat persalinan dan post partum

\section{KESIMPULAN DAN SARAN}

Dalam budaya Banjar pengetahuan tentang tanda bahaya kehamilan dan persalinan dikenal ibu hamil melalui pantangan yang mereka lakukan pada saat hamil dan bersalin. Sebagian pantangan dan kondisi yang dianggap tidak berbahaya dalam kehamilan dan persalinan serta anggapan yang salah tentang usia perkawinan yang sehat, bertentangan dengan kesehatan. Pendidikan rendah, lingkungan tempat tinggal dan paritas termasuk hal yang menyebabkan ketaatan ibu hamil terhadap pantangan.

Pengetahuan tentang tanda bahaya dalam kehamilan dalam budaya Banjar ada yang tidak bertentangan dengan kesehatan karena apabila dilaksanakan tidak berakibat buruk terhadap kesehatan ibu dan bayi. serta pengetahuan lokal ibu ada yang mendukung kesehatan. Keadaan ini perlu didukung/dilestarikan karena bila dilaksanakan akan memberikan efek positif bagi ibu hamil dan bersalin. Berdampak mengurangi bahaya yang mungkin timbul pada saat hamil dan melahirkan.

Saran kepada pembuat kebijakan Perlu perhatian dari pembuat kebijakan dalam kerjasama lintas sektor untuk meningkatkan pendidikan perempuan Banjar. Melalui pendidikan terbukti dapat meningkatkan wawasan / pengetahuan perempuan sehingga mereka mampu menilai kondisi yang berbahaya dan mencari pertolongan yang tepat. Perlu perhatian dari pembuat kebijakan dan pelaksana kesehatan di lapangan untuk meningkatkan pengetahuan ibu hamil melalui penyuluhan dan konseling dalam kehamilan untuk menghilangkan sebagian kepercayaan terhadap kebiasaan pantangan, meluruskan anggapan kondisikondisi yang dianggap tidak berbahaya dalam kehamilan/persalinan dan usia perkawinan yang sehat. Melestarikan pegetahuan lokal yang tidak bertentangan dan mendukung kesehatan dengan memotivasi ibu untuk tetap melaksanakan kebiasaan tersebut dalam kehamilan dan persalinan.

\section{DAFTAR PUSTAKA}

1.Bappenas (2015) Laporan Perkembangan Pencapaian Tujuan Pembangunan Milenium (Millenium Development Goals), Indonesia.

2.BPS, BKKBN, DepKes, ORC Macro (2017) Survei demografi dan Kesehatan Indonesia 2017, Jakarta Indonesia.

3.Thaddeus, S., Maine, D. (2016) Too Far to Walk, Maternal Mortality In Context, Center for Communication Programs, Johns Hopkins University, Baltimore: MD 21202-4024.

4.Lawn, J., Brian, J. and Ross, S.R. (2002) The healty newborn: A Reference Manual For Program Managers, The WHO collaborating Center in Reproductive Health, CDC, Center For Disease and Prevention.

5.Serbanescu, F., Thomas, Clark, Marry, at all. (2019) Healty Newborwn Network:for Health (K4Health), USAID's Office. Center for disease in prevention, USA

6.Bappenas (2017) Angka kematian ibu: Rancang bangun percepatan penurunan angka kematian ibu untuk mencapai sasaran millenium development goals (MDGs). Jakarta: Indonesia.

7. Dasuki, D., Sutrisno, I.J., dan Hasibuan, S (2007) Persepsi Ibu Hamil Terhadap Kehamilan Resiko Tinggi di Kabupaten Purworejo. CHNRL, Yogyakarta.

8.Suhandoyo, T. (2017) Gambaran Persepsi ibu hamil tentang mitos kehamilan di wilayah kerja Puskesmas Dlingo II Bantul Yogyakarta: sekolah Tinggi Ilmu kesehatan: Program Studi Ilmu keperawatan: Yogyakarta 
9.Depkes, R. I. (2010) Rencana Strategis Nasional Making Pregnancy Safer (MPS) di Indonesia 20012010, Jakarta.

10.Depkes, R. I. dan JICA. (2015) Petunjuk teknis penggunaan Buku Kesehatan Ibu dan Anak, Jakarta.

11.KemenKes, R. I. (2012) Buku pelayanan Kesehatan Ibu di tingkat pelayanan dasar dan Rujukan, Direktorat Jenderal pembinaan kesehatan Masyarakat, Direktorat Bina Kesehatan keluarga, Jakarta.

12.Green, L.W., Kreuter, M.W., Deeds, S.G., Pariridge, B.K., and Barilett, E. (2012) Health educational planning, a diagnostic approach. Honston; The John Hopkins University, Myfield Publishing Company.

13.Dinas Kesehatan, (2017) Profil Kesehatan Kota Banjarmasin. Dinas Kesehatan Propinsi Banjarmasin.

14.Sarwono, P. (2018) Ilmu Kebidanan, Yayasan Bina Pustaka, Jakarta.

15.Moustakas, C. (2016) Phenomenogical Research methods, Sage Publications, London .

16.Spradley, J.P, (2007) Metode Etnografi. Yogyakarta: PT.Tiara Wacana Yogyakarta.

17.Simon-Morton, B.G., Green, W.H., Gottlieb, H.H (2005) Intoduction to Health Education and Health Promotion, Waveland Press, Inc, USA.

18.Moleong, J.L (2014) Metodologi Penelitian Kualitatif edisi Revisi, Rosda Karya ISBN: Yogyakarta. 